\title{
ARTICLES
}

\section{BALANCING EQUITY AND EFFICIENCY ISSUES IN THE MANAGEMENT OF SHARED GLOBAL RADIOCOMMUNICATION RESOURCES}

\author{
ROB FRIEDEN*
}

\section{INTRODUCTION}

Radiocommunication spectrum and parking places for satellites have great value ${ }^{1}$ because they provide the physical means for transmitting information, communications, and entertainment ("ICE"), major elements in the global economy. While intangible, like the air, spectrum provides a medium used by transmitting equipment to deliver valuable content to consumers. Orbital parking places for satellites have a closer resemblance to real estate, but the slots used by satellites providing ICE service typically locate in a relatively narrow arc 22,300 miles above the equator. ${ }^{2}$

* Mr. Rob Frieden is a Professor of Telecommunications at Pennsylvania State University.

1 One example of the intrinsic value in radiocommunication spectrum is the amount of money parties are willing to bid for the privilege to use it. The United States Federal Communications Commission ("FCC") has captured billions of dollars for the general treasury from the spectrum auctions it has administered. For an example of FCC auctions, see United States Federal Communications Commission, Wireless Telecommunications Bureau, Auctions Summary, available at http:// wireless.fcc.gov/auctions/summary.html (last visited Feb. 23, 2003).

2 Most communications satellites appear to hover above the earth, thereby providing a fixed target to receive signals from earth and send them back down. Satellite services, including the direct-to-home delivery of video programming, can be provided more cheaply if earth-based antennas do not have to track a moving target. Satellites in a "geostationary" condition orbit the earth once every twenty-four hours. For more background on satellite technology and satellitebased businesses, see PATRICK R. PARSONS \& RoberT M. FRIEDEN, THE CABLE AND 
Access to both of these resources involves high stakes and forces policymakers to balance equity and efficiency concerns. On the equity side, all nations of the world have an equal right of access to these shared resources. ${ }^{3}$ Most nations have signed treaties foreclosing national ownership of space resources, ${ }^{4}$ including orbital slots used by communications satellites. ${ }^{5}$ Likewise, most nations have signed treaties that bind them to administrative rules and regulations regarding classification and registration of spectrum uses. ${ }^{6}$

However, a nation's equal right of ownership and access does not translate into an equivalent level of actual access because developed nations have acted on their earlier needs for spectrum and

SATELLITE TELEVISION INDUSTRIES (1998); ROB FRIEDEN, MANAGING INTERNET-DRIVEN CHANGE IN INTERNATIONAL TELECOMMUNICATIONS (2001).

3 Various treaties and other types of international agreements characterize outer space and radiocommunication resources located there and on earth as having a "common heritage" or as available for the "common benefit of mankind."

A res nullius characterization of outer space would indicate that the heavens belonged to no one; any resource which could be mined or otherwise appropriated would be available for the taking. This sort of "firstcome, first-serve" standard would give the so-called "spacefaring" powers a powerful incentive to expand their efforts to develop space. At the same time, nations unable to afford attempting even to launch satellites into geosynchronous orbit would find themselves increasingly excluded from these resources. Such a characterization would, however, create a first-come, first-serve legal regime. This result would certainly be at odds with the "common heritage" principle.

Jefferson H. Weaver, Illusion or Reality? State Sovereignty in Outer Space, 10 B.U. INT'L. L.J. 203, 221-22 (1992).

4 See, e.g., Treaty on Principles Governing the Activities of States in the Exploration and Use of Outer Space, Including the Moon and Other Celestial Bodies, Jan. 27, 1967, 610 U.N.T.S. 205. Article II of this Treaty establishes that space "is not subject to national appropriation by claim of sovereignty, by means of use or occupation, or by any other means." Id. art. II. For more information on this issue, see Susan Cahill, Give Me My Space: Implications for Permitting National Appropriation of the Geostationary Orbit, 19 WIS. INT'L L.J. 231 (2001); Ricky J. Lee, Reconciling International Space Law with the Commercial Realities of the Twenty-First Century, 4 SING. J. INT'L \& COMP. L. 194 (2000).

5 As part of their commitment to non-appropriation of outer space, nations have agreed to register their launches with the United Nations. Convention on Registration of Objects Launched into Outer Space, Nov. 12, 1974, 1023 U.N.T.S. 15.

6 See Constitution of the International Telecommunication Union, Oct. 14, 1994, S. TREATY DOC. No. 104-34, 1996 WL 569887 [hereinafter ITU Constitution] (outlining the constitution and convention of the ITU), available at http://www.itu.int/aboutitu/basic-texts/constitution.html and http://www.itu. int/aboutitu/basic-texts/convention.html. 
satellite orbital slots, thereby locking up much of the best resources. Globally accepted concerns for efficient use of shared radiocommunication resources favor the implementation of rules that avoid and resolve conflicts regarding access, but this process favors developed nations that typically act earlier than developing nations. Without such rules, which provide a first-in-time, first-inaccess priority, ${ }^{7}$ users of spectrum would have little confidence that they can construct and operate expensive telecommunications networks without interference from other networks. Shared global radiocommunications resources have value if and only if social and commercial transactions can occur across distances without interruption, distortion, or congestion.

Anyone seeking to use spectrum and parking places for satellites typically confronts a number of challenges including:

- scarcity caused by natural limitations in the number of satellites that can operate in the optimal location where they appear motionless and can receive signals and relay them back down to earth;

- scarcity resulting from the laws of physics that limit the number of simultaneous users of the same radio frequency;

- the fact that only some radio frequencies offer the most desirable signal distribution characteristics-e.g., long range geographical coverage;

- significant differences among nations and commercial ventures in terms of access to the substantial funds needed to invest in satellite or radiocommunications facilities such as a local or national cellular telephone network; and

- the substantial headstart in terms of access to the ideal frequencies and satellite orbital slots enjoyed by developed nations and their commercial ventures.

Stakeholders and analysts of the many conflicts over access to shared radiocommunications resources disagree about the best way to achieve the goal of maximizing public benefits. ${ }^{8}$ Pro-

7 "Though some obligation to accommodate remains when conflicts between early and later registrants arise, early registration affords a measure of legitimacy that supports the first registrant's negotiating position. Because the notification process affords preferential treatment to early registrants, it is often characterized as 'first come, first served." Lawrence D. Roberts, A Lost Connection: Geostationary Satellite Networks and the International Telecommunication Union, 15 BERKELEY TECH. L.J. 1095, 1112-13 (2000).

8 One camp asserts that governments need to take aggressive steps to compensate for vast differences in access to ICE resources: "The digital revolution has 
market advocates emphasize the overall contribution to productivity and welfare achieved when parties can competitively bid for ownership rights. Advocates expressing equity concerns reject a parallel between markets for private property ownership rights and a mechanism for coordinating access to resources shared in common by all nations.

Policymakers at both national and multilateral levels need to accommodate and balance both camps. If they fail, stakeholders may lose patience in the process and resort to unilateral, self-help strategies that could include launching satellites and using spectrum without regard to previously registered uses. Likewise, individual nations may ignore global consensus policies regarding the preferred uses for a specific frequency band and the procedure for registering and coordinating the launch of satellites into orbit.

This Article will examine the merits of maintaining, revamping, or abandoning the current administrative processes for managing international spectrum and satellite orbital slots. It will examine efficiency-enhancing strategies including the use of competitive bidding and technological innovations that make it possible for

transformed the lives of many, but also has left untouched the lives of many others. As a result, a large segment of the world population misses out on the tremendous political, social, economic, educational, and career opportunities created by the digital revolution." Peter K. Yu, Bridging the Digital Divide: Equality in the Information Age, 20 CARDOZO ARTS \& ENT. L.J. 1, 2 (2002). Another camp emphasizes the efficiency and productivity gains in relying on marketplace forces to allocate access and use of ICE resources, including radiocommunication spectrum:

The rationales for [government] stewardship and for all-encompassing regulation that were offered in 1927 [at the onset of radio broadcasting] were not strong then; they have not grown any stronger with age. There is a better way. I describe it with a new word: "propertyzing." By that I mean converting the current system of regulatory permits or licenses to use the spectrum into a full-fledged system of property rights ownership.

Lawrence J. White, "Propertyzing" The Electromagnetic Spectrum: Why It's Important, and How to Begin, 9 MEDIA L. \& POL'Y 19 (2000). The latest camp has an even more libertarian view and would rely on technological innovations to replace the government role of doling out property rights: "Thus, the auction solution to the problem of FCC regulation may be no better than the previous system of license allocation .... I argue that the spectrum might be best governed, at least in part, as a commons," i.e., common property available for access by all. Stuart Buck, Replacing Spectrum Auctions with a Spectrum Commons, 2002 STAN. TECH. L. REV. 2, 1 8-9 (2002), available at http://stlr.stanford.edu/STLR/Articles/02_STLR_2/article_pdf.pdf. See also Yochai Benkler, Overcoming Agoraphobia: Building the Commons of the Digitally Networked Environment, 11 HARV. J.L. \& TECH. 287 (1998); Eli Noam, Spectrum Auctions: Yesterday's Heresy, Today's Orthodoxy, Tomorrow's Anachronism. Taking the Next Step to Open Spectrum Access, 41 J.L. \& ECON. 765 (1998). 
more users with possibly different service requirements to share the same spectrum. Having considered the similarities and differences in satellites' spectrum use relative to earthbound uses, the Article concludes that developing a market for orbital slots in lieu of the existing multilateral coordination and registration process would impose more costs and problems than benefits.

The transborder technological characteristics of satellites raise sovereignty, ${ }^{9}$ equity, and jurisdictional issues not triggered by economic and technological initiatives for terrestrial spectrum use. Accordingly, neither international, multilateral forums nor domestic policymaking bodies can jettison the status quo and implement a competitive bidding model for all types of spectrum regardless of geographical coverage and transmission characteristics. In particular, spectrum used for international satellite services and access to the orbital parking places used by satellites do not favor a complete migration to competitive bidding. Proponents of competitive bidding for spectrum have largely ignored the facts that many nations lie under a satellite transmission "footprint," that treaty commitments foreclose national or private ownership of outer space resources, and that the likelihood that auctions would exacerbate parity of access disputes between developed and developing countries. The Article concludes with recommendations on how domestic and international policymaking forums can improve administrative processes, including the brokering of financial inducements to developing nations to refrain from opposing registrations of developed nations, and implementing technologies that promote interference-free sharing.

\subsection{The Current Shift Favoring Efficiency Over Equity Concerns}

Currently both developed and developing nations have begun to favor marketplace decision-making for allocating access rights to portions of the radiocommunications spectrum. For example, many nations have decided to assign spectrum usage rights to the highest bidder for services using frequency bands having limited geographical coverage such as cellular radiotelephone service. Market advocates point to the overall benefits to society when po-

9 "Sovereignty is the situation of the state which has no political superior over it, but is nevertheless bound by international law." Stanley Hoffmann, International Systems and International Law, in 1 THE STRATEGY OF WORLD ORDER: ToWARD A THEORY OF WAR Prevention 134, 164 (Richard A. Falk \& Saul H. Mendlovitz eds., 1966). 
tential users of public resources have to bid competitively for ownership. ${ }^{10}$ For spectrum uses that do not cross borders, marketplace initiatives have great appeal and plausibility, particularly in light of the ability of single nations to implement competitive bidding without adversely impacting spectrum uses and policies in other nations. Absent a cross-border impact, individual nations can choose to foster efficiency, generate revenues for the national treasury, and accrue value for all citizens instead of the lucky few who previously secured spectrum license grants without payment.

Equity advocates have expressed concerns that even for domestic-only spectrum uses, complete faith in marketplace resource allocation ignores the broader national and societal interest.11 Market countervailing considerations include supporting spectrum access by underrepresented constituencies-e.g., women, minorities, the poor, small businesses, and rural residents - or by particular user groups that serve national security and other compelling interests-e.g., defense, intelligence gathering, homeland security, and public safety government agencies.12 Equity considerations favor affirmative steps to ensure that elites and corporations with deep pockets do not capture all spectrum access opportunities.

10 See Peter Cramton, The Efficiency of the FCC Spectrum Auctions, 41 J.L. \& ECON. 727 (1998); Thomas W. Hazlett, Assigning Property Rights to Radio Spectrum Users: Why Did FCC License Auctions Take 67 Years?, 41 J.L. \& ECON. 529 (1998); William H. Melody, Spectrum Auctions and Efficient Resource Allocation: Learning from the $3 G$ Experience in Europe, 3 INFo 5 (2001); Pablo T. Spiller \& Carlo Cardilli, Towards a Property Rights Approach to Communications Spectrum, 16 YALE J. ON REG. 53 (1999).

11 [Lesser Developed Countries ("LDCs")] and the developed nations hold fundamentally different beliefs as to the scarcity of usable electromagnetic spectrum. Developed countries maintain that electromagnetic spectrum, although a finite natural resource, is sufficient in supply to fulfill worldwide demand, provided it is used in an efficient, high utility, technologically advanced manner. LDCs maintain that electromagnetic spectrum is a scarce natural resource, inequitably distributed in a manner favoring established use.

William Kummel, Spectrum Bids, Bets, and Budgets: Seeking an Optimal Allocation and Assignment Process for Domestic Commercial Electromagnetic Spectrum Products, Services, and Technology, 48 FED. COMM. L.J. 511, 540 (1996).

12 "It can also be expected that in future the principles of public service and global public interest in all forms of telecommunications, including satellite telecommunication, would be further compromised. Some countries, mainly the poor and developing ones, would be denied a significant amount of benefits of telecommunication satellite technology." Ram S. Jakhu, Safeguarding the Concept of Public Service and the Global Public Interest in Telecommunications, 5 SING. J. INT' L \& COMP. L. 71, 100 (2001). 
Likewise, these considerations support the view that government agencies should not have to compete against commercial ventures for spectrum.

Equity considerations notwithstanding, marketplace remedies have gained favor among the ranks of both policymakers and academics. Current debates take as a foregone conclusion the public benefits of competitive bidding, and instead concentrate on finetuning the process, including the possibility of extending its reach. ${ }^{13}$ For example, the United States Federal Communications Commission's Spectrum Policy Task Force has recommended the possible use of competitive bidding "to resolve mutually exclusive applications for global and international satellite services" 14 notwithstanding a law that prohibits such a practice..$^{15}$

\subsection{Cross-Border Spectrum and Satellite Uses Amplify Equity Con- cerns}

Equity concerns become more compelling when users in two or more nations have to share radiocommunications resources and coordinate uses. The limitations of physics, politics, jurisdiction, and international treaties complicate the process for sharing. They refute the simple assumption of some economists that shared global radiocommunication resources are identical to real estate such that treaties between governments could "extend the property rights system ... into the international realm." 16 Many radio

13 See, e.g., EVAN KWEREL \& John WILliams, A Proposal for a RAPID TRANSITION TO MARKET ALLOCATION OF SPECTRUM, FCC Working Paper No. 38 (2002) (proposing a methodology for efficiently restructuring a large amount of encumbered spectrum), available at http://hraunfoss.fcc.gov/edocs_public /attachmatch/DOC-228552A1.pdf; Joseph M. Ward, Comment, Secondary Markets in Spectrum: Making Spectrum Policy as Flexible as the Spectrum Market it Must Foster, 10 COMMLAW CONSPECTUS 103 (2001) (following the evolution of spectrum policy in the context of assignments and transfers).

14 Spectrum Policy Task Force, Federal Communications Commission, Report, ET Docket No. 02-135 at 42 (2002), available at http:/ / hraunfoss.fcc.gov

/edocs_public/attachmatch/DOC-228542A1.doc.

15 [The FCC] shall not have the authority to assign by competitive bidding orbital locations or spectrum used for the provision of international or global satellite communications services. The President shall oppose in the International Telecommunication Union and in other bilateral and multilateral fora any assignment by competitive bidding of orbital locations or spectrum used for the provision of such services.

International Telecommunications Act, P.L. 106-180, 114 Stat. 48 (2000).

16 White, supra note 8 , at 37. 
services provide long-range communications, and most satellites have signal coverage "footprints" that span entire regions. Accordingly, no single nation or private venture can act unilaterally because most nations have committed to a multilateral approach for shared access to radiocommunications resources. Any decision by one nation to launch a communications satellite or to activate a new radiocommunications facility can have a direct and potentially adverse impact on other nations, particularly ones nearby.

Simply analogizing radiocommunications resources to real estate ignores the fact that privatizing spectrum can foreclose access rights of others, including citizens in nearby countries. A nation can recognize private property ownership rights and can establish binding and effective rules for the buying and selling of real estate within the country. However, such a marketplace system for radiocommunications resources would involve the application of rules on an extraterritorial, cross-border basis.

One can appreciate the attractiveness of privatizing radiocommunications. Developed and developing countries alike stand to benefit financially from a one-time infusion of cash into their national treasury when converting freely-licensed spectrum grants to a competitive bidding mechanism such as auctions. However, long-term complications and deficiencies in privatization of global radiocommunications resources offset much of the near-term gain, especially for the trafficking in satellite orbital slots. Developing nations stand to lose more from a commercialized market than from one characterized by multilateral coordination, compromise, and consensus building.

\subsection{International Governance Mechanisms}

When it comes to radio spectrum and satellite orbital slots, nations collectively and individually have rejected either an absolute market-driven or an equity-driven model for allocating, registering, and coordinating usage. On a multilateral basis, nations look to a specialized agency of the United Nations, the International Telecommunication Union ("ITU"), to erect and administer mechanisms for conflict avoidance and resolution. While lacking an enforcement mechanism, the ITU provides a forum for the ventilation of both efficiency and equity arguments.

ITU decisions typically occur without a formal vote because the forum seeks to build a consensus. Nations often agree to a single spectrum allocation or technical standard based on enlightened 
self-interest-i.e., the sense that uniformity will reduce operating costs, speed commercial rollout of new technologies, and reduce confusion. When nations fail to reach a consensus at the ITU, manufacturers may have to produce multiple equipment product lines and consumers may incur higher costs-e.g., no single cellular telephone will function at all locations.

The ITU has established shared "rules of the road" in exchange for the relinquishment of some degree of national sovereignty and self-determination. Nations participating in the ITU agree to participate in a spectrum allocation process that identifies specific uses for particular portions of the radio spectrum. Nations agree to register their spectrum and satellite orbital slot requirements on an asneeded basis as well. The ITU model provides an effective administrative vehicle to register spectrum and orbital slot usage and to mediate disputes. However, it cannot prevent "warehousing" of spectrum-i.e., registering unneeded uses that has the effect of foreclosing others, who have near-term requirements, from achieving conflict-free registrations. In addition, the ITU administrative process cannot foreclose attempts to register "paper satellites" i.e., filing for the registration of orbital slots for satellites with no realistic probability of launch. ${ }^{17}$

Warehousing of spectrum and filing paper satellite registration applications have the doubly harmful effect of: 1) blocking productive use by others with near-term needs; and 2) thwarting laterin-time registration by developing nations whose requirements and ability to finance usage typically arise after developed nations already have enjoyed first choice opportunities. Only on rare occasions has the ITU deviated from a "first filed, first registered" model by reserving spectrum and orbital slots for developing nations. ${ }^{18}$

17 For background on the ITU satellite orbital slot registration process and the administrative difficulties resulting from paper satellite registration filings, see Albert N. Delzeit \& Robert F. Beal, The Vulnerability of the Pacific Rim Orbital Spectrum Under International Space Law, 9 N.Y. INT'L L. REV. 69 (1996); Jannat C. Thompson, Space For Rent: The International Telecommunications Union, Space Law, and Orbit/Spectrum Leasing, 62 J. AIR L. \& CoM. 279 (1996); Henry Wong, Comment, The Paper "Satellite" Chase: The ITU Prepares for its Final Exam in Resolution 18, $63 \mathrm{~J}$. AIR L. \& COM. 849 (1998).

18 The most successful application of equity principles to the geostationary orbit arose out of negotiations during the sessions of the Space World Administrative Radiocommunications Conference held in 1985 and 1988. The result was a compromise that produced a hybrid system which combined the "first come, first served" system with an a priori allotment sys- 
On occasion, developing countries have resorted to unilateral "self-help" strategies to compensate for their inferior access and, perhaps, in retaliation to the superior access enjoyed by developed nations. Such strategies have included the unilateral claim by several equatorial countries to national ownership of satellite orbital slots situated directly above them. ${ }^{19}$ However, no nation has successfully extracted payment for relinquishing unneeded and financially unviable ITU registrations of frequencies. A possible solution to the inferior, later-in-time access problem encountered by developing nations may lie in developing ways to aggregate funds and telecommunications service demand so that spectrum and orbital slot registrations may proceed earlier than if a single nation sought to construct and operate a costly network. ${ }^{20}$ Another potential remedy lies in requiring wealthy nations to use new technological tools that can free up spectrum for use by developing nations unable to afford such cutting-edge innovations.

\subsection{Pooling Investment in International Satellites to Promote Access}

Multilateralism has also worked to promote widespread access to satellite technology, including the opportunities for developing nations to participate in the ownership and management of a global satellite carrier. The pooling of investment among nations helped spread technological and financial risk across a larger group of participants. It also expedited the use of satellite technol-

tem. Under the plan, each ITU Member was granted an allotment consisting of a nominal orbital position which represented a center point around which to base a maximum ten degree arc on the geostationary orbit, eight hundred megahertz of bandwidth, and a designated service area roughly equivalent to each Member's terrestrial borders. The allotments should not be confused with actual reserved assignments of positions and frequencies for fixed satellite service. They more closely resemble a right of coordination priority. The actual positions and frequencies remain available for use under the traditional allocation process; it is only when a Member begins the process of notification that the allotment plan becomes a factor in the distribution process.

Roberts, supra note 7, at 1128.

19 Declaration of the First Meeting of Equatorial Countries of Dec. 3, 1976, available at http://www.nasda.go.jp/lib/space-law/chapter_2/2-2-1-2_e.html.

20 See, e.g., Lee Berger, Proposed Legal Structure for the Silksat Satellite Consortium: A Regional Intergovernmental Organization to Improve Telecommunications Infrastructure in Central Asia and the Trans-Caucasus Region, 33 LAW \& POL'Y INT'L Bus. 99 (2001) (describing plans for a satellite telecommunications system for the Central Asia and Trans-Caucasus region). 
ogy for commercial communications in addition to established space exploration, defense, and intelligence-gathering missions.

Satellite investment pooling by many nations follows a cooperative model previously used in a number of agricultural applications. Where one unit of a product has little, if any, difference with another unit, this fungible characteristic supports aggregation by numerous producers. For example, all the dairy or wheat farmers in a region can pool their investments and establish a local processing and storage facility for handling all of the farmers' output. This facility helps the farmers obtain the best possible prices for their products and also creates the possibility for some degree of value-added processing, e.g., milling the wheat and pasteurizing the milk.

Satellite cooperatives aggregated demand and made it possible to establish a large inventory of capacity. The International Satellite Organization ("INTELSAT"), 21 European Satellite Organization ("EUTELSAT"), and International Maritime Satellite Organization ("INMARSAT") helped expedite the commercialization of space radiocommunications and made it possible for developing nations to participate with a small initial investment. The satellite cooperatives had charters, negotiated on a multilateral, inter-governmental basis, that emphasized the promotion of world peace and understanding through widespread access and use of satellites. These cooperatives operated as businesses, but had missions that emphasized access and service instead of profit maximization.

The global and regional satellite ownership model helped make it possible for developing nations to afford satellite network access. Even the poorest and smallest nations could connect to a global satellite constellation with a minor investment in the cooperative through the payment of affordable rates for a small amount of satellite capacity and installation of one or more earth station transmitting and receiving facilities. However, this model lost much of its financial and policy support over time. As satellite technology evolved and as the marketplace for satellite services developed, the cost of constructing, launching, and operating a satellite network dropped substantially. . Demand for satellite services, particularly delivery of video content to broadcast and cable television net-

21 For background on the formation of INTELSAT and its privatization see Alexandra M. Field, INTELSAT at a Crossroads, 25 LAW \& PoL'Y'INT'L BUS. 1335 (1994); Rob Frieden, Privatization of Satellite Cooperatives: Smothering A Golden Goose?, 36 VA. J. INT'L L. 1001 (1996). 
works, stimulated private entrepreneurs to think they could enter the market and thrive. The incumbent satellite operators, such as INTELSAT, sought to thwart such competition on grounds that it would cause economic harm and hinder the cooperatives' ability to serve high cost, rural locations, and to facilitate investment and participation by developing nations.

Over time, the satellite cooperatives acted much like cartels intent on preserving their financial well-being at the expense of others. Nations with government or private-carrier investors in satellite cooperatives had executed treaty-like documents, designed to confer special privileges and immunities, so that the cooperatives could achieve their mixed business and political mission. This special status helped reduce the cost of setting up and operating the cooperatives, but it also created a semi-diplomatic organization insulated from many marketplace forces. For example, the creators of INTELSAT sought to ensure that the cooperative would capture most of the global telecommunications traffic by agreeing not to authorize separate international satellite operators that collectively would cause economic harm to the cooperative. Additionally, the cooperatives and their employees enjoyed special exemptions from tax and other domestic charges imposed by the nation where the cooperatives were based and where satellites were bought and launched.

In the mid-1980s, the United States, followed by other nations, permitted commercial satellite alternatives.22 These systems have achieved marketplace success without adversely affecting the ability of satellite cooperatives to achieve their mission. Management of these cooperatives, having failed in their bid to block competition, turned their attention to finding ways to compete more effectively. In the spirit of "if you can't beat them, join them," the managers of INTELSAT, INMARSAT, and EUTELSAT sought to privatize and to become commercial ventures. ${ }^{23}$ Efforts were undertaken to ensure "lifeline" access by nations unlikely to benefit

22 See Establishment of Satellite Systems Providing International Communications, 101 F.C.C.2d 1046 (1985), modified on reconsideration, 61 Rad. Reg. 2d (P\&F) 648 (1986) (establishing regulatory policies to consider application for satellite systems providing international communications services separate from INTELSAT).

23 See Francis Lyall, On the Privatisation of INTELSAT, 5 SING. J. INT'L \& COMP. L. 111 (2001) (describing the conversion of INTELSAT from an intergovernmental organization into a private company). 
from competitive satellite markets. ${ }^{24}$ However, too little time has passed to confirm that spun-off and commercialized former cooperatives will not further handicap developing nations and worsen the gap between nations in terms of access to telecommunications and information-processing services. At the very least, developing nations need to voice their concerns about prospective radiocommunications resource requirements and seek compromises with developed countries.

\section{PREFERENCES, POWER, AND POLICYMAKING}

To understand the reasons behind the push for market resource allocation alternatives, one should consider the strengths and weaknesses in the incumbent ITU and satellite cooperative models. At their best, these models have promoted timely access to new technologies and services by users in developing nations, often provided helpful conflict avoidance and resolution services, and promoted shared "rules of the road" that reduced cost, enhanced operational efficiency, and gave a voice to developing nations. At their worst, these models have forestalled introduction of new technologies and services, helped extend developed-nation domination of spectrum and orbital slots, and failed to prevent gaming and manipulation of the registration process.

\subsection{International Telecommunication Union}

The ITU strives to lend its "good offices" for resolving issues pertaining to spectrum use, telecommunications policies, standards, and development. ${ }^{25}$ However, the ITU can shape uniform

24 For example, the United States Congress enacted the Open-Market Reorganization for the Betterment of International Telecommunications Act, P.L. 106$80(2000)$, to ensure that privatized cooperatives do not have the ability to leverage their previous status to secure anticompetitive advantages, and to ensure a small residual organization continues to provide core, lifeline services to developing nations, including ones lacking access to submarine cable capacity. For access to the legislative history on the ORBIT Act, see Bill Summary and Status for the 106th Congress, at http://thomas.loc.gov/cgi-bin/bdquery/z?d106:SN00376:|TOM:/ bss/d106query.html.

25 For background on the ITU organization structure and history, see George A. Codding, Jr., The International Telecommunications Union: 130 Years of Telecommunications Regulation, 23 DENV. J. INT'L L. \& POL'Y 501 (1995); Francis Lyall, The International Telecommunication Union and Development, 22 J. SPACE L. 23 (1994); Harold M. White, Jr. \& Rita Lauria, The Impact of New Communication Technologies on International Telecommunication Law and Policy: Cyberspace and the Restructuring of the International Telecommunication Union, 32 CAL. W. L. REV. 1 (1995). 
operational rules and register interference-free spectrum uses if and only if all nations recognize its legitimacy and comply with its regulations, policies, and recommendations. At various times both developed and developing nations have expressed frustration with the pace, quality, and effectiveness of ITU decision-making. ${ }^{26}$ Some developing nations have claimed that the developed nations unfairly set the policymaking agenda by fully staffing the numerous voluntary study groups and other forums that pose questions, provide answers, and recommend rules. ${ }^{27}$ Stakeholders in developed nations complain about the slow pace of decision-making and the apparent inability of the ITU to respond quickly to changed circumstances-for example, the need to revise rules and to allow shared use of spectrum when technological innovations make it easier to do so without harmful interference.

The ITU strives to balance often conflicting interests in efficient use of spectrum and satellite orbital slots on one hand, and in promoting equity concerns, such as promoting access by developing countries, on the other hand. Article 44 of the ITU Constitution states that:

Members shall endeavour to limit the number of frequencies and the spectrum used to the minimum essential to provide in a satisfactory manner the necessary services. To that end, they shall endeavour to apply the latest technical advances as soon as possible.

26 Although a lot has already been achieved in the right direction by the ITU-which "can reform", as history has demonstrated over decades many think nevertheless that even more needs to be done. This reform process is, therefore, still ongoing and new reform proposals will in all likelihood again be on the table....

Alfons A.E. Noll, The ITU in the 21st Century, 5 SING. J. INT'L \& COMP. L. 63, 68-69 (2001).

27 North-South debates concerning access to information and equitable allocation of spectrum have often mired the international telecommunications negotiations of the last two decades. Many believed that the information and communications gaps between the North and South could be bridged only by normative restructuring schemes under the rubric of the New World Information and Communications Order (NWICO).

J.M. Spectar, Bridging the Global Digital Divide: Frameworks for Access and the World Wireless Web, 26 N.C. J. INT'L L. \& COM. REG. 57 (2000). 
In using frequency bands for radio services, Members shall bear in mind that radio frequencies and the geostationarysatellite orbit are limited natural resources and that they must be used rationally, efficiently and economically, in conformity with the provisions of the Radio Regulations, so that countries or groups of countries may have equitable access to both, taking into account the special needs of the developing countries and the geographical situation of particular countries. 28

The ITU has established an administrative process for allocating spectrum uses and for registering a nation's use of both spectrum and satellite orbital slots. ${ }^{29}$ Generally the ITU process offers first-filed, first-in-priority recognition. Because the ITU lacks an enforcement mechanism, it can only legitimize, rather than guarantee, a spectrum use and orbital slot registration. Likewise, the ITU, in compliance with other treaties executed under the auspices of the United Nations, cannot provide a mechanism for national appropriation or ownership of resources located in outer space, such as satellite orbital slots. ${ }^{30}$ These twin limitations severely constrain the flexibility and effectiveness of the ITU.

The ITU can provide effective conflict avoidance and resolution services if member nations agree to comply with its recommendations and findings, which do not have the force of a treaty obligation. ${ }^{31}$ Likewise, the ITU cannot readily discipline member nations from "papering" the registration system with spectrum and satellite registrations designed to foreclose uses by operators in other nations, extract payments from others with more immediate needs,

28 ITU Constitution, supra note 6 , ch. VII, art. 44.

29 For background on the ITU spectrum allocation and satellite orbital slot registration process, see FRIEDEN, supra note 2, ch. 6 .

30 In short, the Outer Space Treaty sets forth the most fundamental principles of space law, including that the exploration and use of outer space shall be for the benefit of all mankind, that outer space is not subject to national appropriation by claim of sovereignty, and that each State party shall authorize, supervise, and be responsible for the space activities of its nationals.

Franceska O. Schroeder, The U.N. Treaties on Outer Space and Their Effect on Space Business, 16 AIR \& SPACE LAW. 8 (2002).

31 Only the ITU Constitution and Convention have the force of a treaty. 
or secure priority future access based on the possibility of a spectrum need.

Few observers would dispute that the ITU spectrum and orbital slot management process creates the potential for congestion in spectrum and orbital slot usage. Much of the potential for interference arises from speculative paper filings of phantom spectrum and satellite use proposals that lock up and warehouse currently unneeded spectrum and orbital slots. The ITU largely lacks "due diligence" procedures that would require applicants to demonstrate timely progress toward the actual launch of a satellite and to pay for the costs incurred by the ITU to process applications and coordinate among existing and prospective registrants. ${ }^{32}$ Currently the ITU cannot readily distinguish real and legitimate filings from speculative and unrealistic ones. ${ }^{33}$

Nevertheless, the process has muddled through with relatively rare instances of actual interfering spectrum uses by terrestrial or satellite uses. Even with a relatively successful record, the ITU registration process has frustrated stakeholders in light of the time it takes and the use of a first-filed, first-registered method that places a premium on when a nation files for a spectrum or orbital slot use. National governments and private enterprises recognize the advantage in commencing the ITU registration process early and of-

32 For a critique of the current registration process and a reform proposal, see Captain Roscoe M. Moore, III, Business-Driven Negotiations for Satellite System Coordination: Reforming the International Telecommunication Union to Increase Commercially Oriented Negotiations over Scarce Frequency Spectrum, 65 J. AIR L. \& COM. 51 (1999).

33 The ITU recognizes the problem, but so far only non-binding resolutions have proposed the imposition of more burdensome due diligence requirements coupled with higher fees to cover the cost of coordinating possibly interfering uses. "The problem of 'paper satellites' has been recognized for years, however, satellite operators have been reluctant to pay processing fees and some developing countries argue that fees contravene the international principles of fair and equitable access to orbital slots and the frequency spectrum that governs them." Press Release, ITU, Scrambling for Space in Space: ITU Plenipotentiary to Tackle 'Paper Satellite' Problem (Sept. 16, 2002), available at http://www. itu.int/ newsarchive/press_releases/2002/21.html. See also International Telecommunication Union, Plenipotentiary Conference (Minneapolis, 1998) [hereinafter Plenipotentiary Conference], Res. 86, Coordination and Notification Procedures for Satellite Networks (seeking simplification and cost savings in the registration process for satellite networks spectrum use), prior version available at http://www.itu.int/aboutitu/basic-texts/resolutions/res86.html; Res. 88, Processing Charges for Satellite Network Filings and Administrative Procedures (recommending cost-based processing charges for satellite filings), available at http://www.itu.int/council/adhoc-snf/Res88rev-e.doc. 
ten. Developing nations typically lack the resources and wherewithal to act early, making it all the more difficult for them to achieve success for later-in-time applications.

To compensate for developing nations' comparatively inferior ability to win in a filing race, various equity-based equalizing proposals and self-help strategies have surfaced. The ITU has established a limited alternative to the first-in-time, first-in-right (a posteriori) registration. When allocating additional spectrum for satellite services, the ITU decided to accord each member nation priority access to at least one orbital slot. ${ }^{34}$ This a priori system provides a preferred access opportunity, but provides neither an orbital slot registration nor a legal right. As well, this process may emphasize equity at the expense of efficiency, particularly if a developing nation claims priority access to an orbital slot, despite having no practical capability to finance the construction, launch, and operation of a satellite within the seven-year timetable established by the ITU. ${ }^{35}$ Having qualified for a legitimate, preferred access opportunity, a developing nation might foreclose, or at least delay, the use of an orbital slot by a developed nation ready and able to use the orbital slot immediately.

\subsection{The Satellite Cooperative Model}

While the ITU struggles to maintain its legitimacy and relevancy, the satellite cooperative model has been overtaken by substantial technological innovations and changed commercial circumstances. Technological innovations have reduced the cost and increased competition in satellite manufacture and launch. While it made sense to pool risk and investment in the initial migration from space exploration to commercial use, a robust, competitive satellite industry has evolved. Concerns about making it possible for developing nations to access satellite technology have abated in

34 An a priori system is a planned, or engineered, system in which the ITU allots a "nominal" orbital slot with a certain arc or a portion of the GSO to each member state. When a provider wishes to use a nominal slot, it must seek assignment from the member country. If the country makes the assignment to the service provider, the nominal position may be adjusted to a real position within the arc.

Adrian Copiz, Scarcity in Space: The International Regulation of Satellites, 10 COMMLAW CONSPECTUS 207, 215-16 (2002).

35 ITU Radio Regulation 1042 creates a five-year timetable within which a satellite must become operational. ITU Radio Regulation 1550 provides a two-year extension of time. 
view of market entry by private satellite ventures and a larger set of national or regional satellite options.

The cooperative model helped foreclose early satellite orbital slot access disputes because nations collectively invested in a global constellation of satellites instead of launching their own. ${ }^{36}$ This model helped expedite the development of a satellite alternative to submarine cables by ensuring widespread and geographically dispersed use of satellites, thereby fully exploiting the wide geographical coverage of a satellite located in a geostationary orbit 22,300 miles above earth. The proliferation of satellite access options has eliminated the need for investment pooling, but has worsened congestion in the geostationary satellite orbital arc.

The satellite cooperative model now has diminished significance, both because management of the cooperatives sought a more flexible environment and because an increasing number of nations considered it prudent to authorize private competitive alternatives. ${ }^{37}$ A small residual International Telecommunications Satellite Organization continues to satisfy INTELSAT's previous treaty-based commitments to promote "world peace and understanding" 38 through widespread international satellite ownership and access opportunities. This core service mission may become more difficult if the substantially streamlined INTELSAT encoun-

36 INTELSAT functioned as a "financial cooperative." Each Signatory made capital contributions and received repayment and compensation proportional to the amount invested, in accordance with a schedule determined by the Board of Governors. Though capital contributions differed in size, any user paid the same rate for each type of service. The Meeting of Signatories fixed rates for all services universally, creating the economic effect of holding down prices for services in the developing world (where sparse satellite services would normally be more expensive) and raising them higher in the developed world (where, because of more competition and supply, rates would otherwise be less expensive).

Berger, supra note 20 , at 112-13.

37 For more extensive analysis of INTELSAT's privatization, see Frieden, supra note 21; Lyall, supra note 23; Henry Wong, 2001: A Space Legislation Odyssey-A Proposed Model for Reforming the Intergovernmental Satellite Organizations, 48 AM. U. L. REv. 547 (1998).

38 Agreement Relating to the International Telecommunications Satellite Organization "INTELSAT", Aug. 20, 1971, 23 U.S.T. 3813, 3814. The FCC has approved INTELSAT's privatization and a public offering of stock will occur. INTELSAT LLC, 15 F.C.C.R. 15,460, 15,461-62 (2000). See also FCC Report to Congress as Required by the Orbit Act, 16 F.C.C.R. 12,810 (2001); FCC 02-170, 17 F.C.C.R. 11,458 (2002); International Telecommunications Act, P.L. 106-180, 114 Stat. $48(2000)$. 
ters difficulty in registering future orbital slot requirements and in financing satellites.

\subsection{Some Self-Help Strategies Mimic Private Auctions}

The ITU has refrained from allowing member nations and their public or private ventures to negotiate financial inducements as a way to resolve interference and access conflicts. Nevertheless, one should consider whether such a mechanism might work even under the auspices of the ITU, particularly in light of instances where the lack of such a forum has generated costs and delays a stakeholder might gladly pay to remove. Absent a legitimate and central forum, which can consider monetary inducements to resolve conflicts, some parties have sought financial compensation on a unilateral basis by offering to transfer or withdraw registrations. Others have used the ITU registration services of nations offering "flags of convenience." Rather than join the lengthy queue of registration requests from a developed nation, such as the United States, an incumbent or prospective satellite operator might seek expedited or preferential treatment by seeking registration from a developing country with no backlog.

\subsection{Paper Satellites and Nuisance Payments}

Paper satellite filings provide an example of self-help retaliation against the real or perceived inequity in the ITU administrative process. Nations lacking the commercial demand or financial resources to construct, launch, and operate a satellite network nevertheless can exploit the ITU orbital slot registration system to extract compensation, or at least to vent their frustration by causing processing delays. For example, between 1988 and 1990 the nation of Tonga attempted to register sixteen orbital slots. ${ }^{39}$ The princi-

39 From 1988 to 1990 , when Tonga made the filings on behalf of Friendly Islands Communications ("Tongasat"), the ITU system permitted a country to register a position for up to nine years before a satellite was launched. Tonga's action "outraged" the international community because it "lacked a genuine need" for so many orbital allotments in the Pacific Rim portion of the GSO. Tonga eventually withdrew its request for ten of the sixteen allotments, and, in 1991, it acquired six allotments. But, Tongasat further angered the international community by leasing one allotment to Unicom, a Colorado company, and auctioning off the remaining five allotments ....

Copiz, supra note 34, at 208. 
pals of Tongasat, the private venture for which the Tonga government filed the satellite registration applications, made several publicized overtures to incumbent satellite operators offering to relinquish some or all of the attempted registrations in exchange for financial compensation. One could easily infer that the consultant advising Tonga's government knew that the ITU registration process lacked sufficient financial and procedural prerequisites, due diligence requirements, and benchmarking that might have stymied paper applications. Only recently has the ITU considered imposing registration fees to compensate it for the costs incurred in processing a proposed orbital slot registration. ${ }^{40}$ The ITU still lacks adequate due diligence standards or a timetable of deliverables that would require prospective registrants to demonstrate progress toward a timely launch. Absent these safeguards, a nation with absolutely no ability to launch dozens of satellites, or even one, still could have representatives claim a right to coordinate the future interference-free operation of these paper satellites with existing and future satellites operating in the region.

Arguably, the instigators of Tonga's satellite registrations had a mind to create a private auction. As a sovereign nation and member of the ITU, Tonga had the right to use the registration services of the ITU. While guilty of seeking to register satellites for which it practically never would launch, the nation of Tonga violated only the spirit of the satellite orbital slot registration procedures. Under current conditions, it would take only a few more paper satellite registration applications for the ITU administrative process to implode. However, as the first mover in this strategy, Tonga staked out orbital slot claims and in effect tried to create a market to be bought out of these claims. In view of Tonga's efforts to "monetize" its orbital stake claims, one can anticipate future scenarios where more nations might try to extract sizeable nuisance payments, or perhaps free or discounted satellite capacity in exchange for abandoning their claims. ITU Member nations including Gibraltar and Papua New Guinea have offered to handle the ITU registration process for satellite network proposals based in the United States but designed to provide services to many nations including the sponsoring registrant.

2.5. Defects in the ITU Administrative Process

40 See Plenipotentiary Conference, supra note 33, at Res. 86 and 88. 
In addition to encouraging self-help and trafficking, the current ITU spectrum and orbital slot registration process has resulted in inefficient use of global resources, delay, and higher costs. The ITU limits flexibility and speed of access by imposing an international template on spectrum uses and registration. The ITU uses a block allocation method for allocating spectrum that subdivides usable spectrum into service-specific slivers of priority use. While the international allocation constitutes a recommendation without the force of a treaty, and nations may opt out by taking a "reservation" to any specific allocation, most domestic regulatory agencies implement the ITU consensus decision. 41

Allocating spectrum in blocks limits user flexibility, but a global consensus on uses theoretically can reduce costs, promote single equipment production lines, enhance connectivity across borders, and support single or compatible operating standards. In economic terms, consensus spectrum allocations promote positive network externalities ${ }^{42}$ in terms of cross-border compatibility of equipment and services. For example, most nations have agreed to the consensus spectrum allocation for satellite frequencies. This means that all nations illuminated by a satellite footprint can access the same satellite having agreed on what frequencies the satellite will operate and what technical parameters transmitting and receiving earth stations will use. When nations fail to reach such consensus, consumers face equipment and operating frequency incompatibility as has occurred with cellular radiotelephone service. If the nations of the world had agreed on a single spectrum allocation for cellular radio service, there might have evolved a single transmission standard so that a single transceiver could operate throughout the world.

While spectrum block allocations can promote the accrual of positive network externalities, ironically they also can frustrate progress achieved through technological innovations. For example, transceiver miniaturization now makes it possible to use the

41 See, e.8., The Establishment of Policies and Service Rules for the NonGeostationary Satellite Orbit, Fixed Satellite Service in the Ku-Band, Report and Order, IB Docket No. 01-96, 17 F.C.C.R. 7841 (2002) (implementing co-frequency sharing arrangements among different types of satellite operators consistent with policies adopted by the ITU's 2000 World Radiocommunication Conference).

42 A network externality arises when a good becomes more valuable to a user if more users adopt the same good or compatible ones. JEAN TIROLE, THE THEORY OF INDUSTRIAL ORGANIZATION 405 (1992). See also Michael L. Katz \& Carl Shapiro, Network Externalities, Competition, and Compatibility, 75 AM. ECON. REv. 424 (1985). 
same satellite radiotelephone when on land, in an aircraft, and on the high seas. However, before the onset of this innovation, the ITU established separate spectrum allocations for land mobile, aeronautical, and maritime satellite mobile services based on the then appropriate assumption that satellite terminals would remain fixed in only one of the three different locations. The ITU has not yet fully acknowledged the newly achieved ability to use a satellite handset across the three different operating environments thereby maintaining a now unnecessary limitation on the range of frequencies available.

\subsection{Spectrum Management Initiatives}

After decades of effort, ${ }^{43}$ economists have generated an increasingly positive reception among legislators and policymakers to assertions that market forces can apply to the allocation and use of radio spectrum. Economists consider spectrum no different from real estate and other types of property:

Land is finite; the same is true of spectrum. Productive land is "scarce"; the same is true of spectrum. Different types of land are inherently better suited for different uses; the same is true of spectrum. Technological change can improve the efficiency of the use of land; the same is true of spectrum. Technological change can expand the amount of land that is considered usable and productive; the same is true of spectrum. Technological change can alter the uses to which land should economically be devoted; the same is true of spectrum. Changing economic demands (often in-

43 Economists have long argued that market-driven allocation and use of spectrum serves efficiency and welfare-enhancing goals. See, e.g., Ronald Coase, The Federal Communications Commission, 2 J.L. \& ECON. 1 (1959) (discussing the evolution of the FCC and its powers); Cramton, supra note 10; Arthur S. DeVany, et al., A Property System for Market Allocation of the Electromagnetic Spectrum: A LegalEconomic-Engineering Study, 21 STAN. L. REV. 1499 (1969) (discussing the legal, economic, and engineering issues raised by the creation of a property system in the electromagnetic spectrum); Thomas W. Hazlett, supra note 10; Glen O. Robinson, Spectrum Property Law 101, 41 J.L. \& ECON. 609 (1998); Gregory L. Rosston \& Jeffrey S. Steinberg, Using Market-Based Spectrum Policy to Promote the Public Interest, 50 FED. COMM. L.J. 87 (1997) (addressing spectrum policy questions); David Salant, Auctions and Regulation: Reengineering of Regulatory Mechanisms, 17 J. REG. ECON. 195 (2000) (focusing on spectrum auctions); Douglas W. Webbink, Radio Licenses and Frequency Specirum Use Property Rights, 9 COMM. \& THE L. 3 (1987) (noting property rights within the frequency spectrum). 
tertwined with technological change) can alter the efficient uses to which land should be put; the same is true of spectrum. Some uses of land may interfere with neighboring uses of land; the same is true of spectrum. ${ }^{44}$

Economists quite properly recognize the inefficiency in nonmarket allocation mechanisms, such as that exercised by domestic regulators such as the Federal Communications Commission in concert with the multilateral, ITU block allocation process. ${ }^{45}$ Economists have persuasively argued that the current "regulatory system ... systematically suppress[es] competitive entry, block[s] efficient spectrum use, and protect[s] obsolete technologies from innovate challenge." 46 The block allocation method established by the ITU and implemented domestically by national regulatory agencies establishes a top-down, lock-step symmetry at the expense of user flexibility, particularly when technological innovations enhance the potential for non-interfering, but different types of services using the same spectrum. Because the allocation process coupled with licensing users tends to foreclose timely adjustments, incumbent users benefit from such inertia. While having nothing more than a spectrum operating permit, incumbents act as though their licenses confer a right to use assigned spectrum in perpetuity, without having to share and without having to pay for the privilege.

National regulatory agencies justify their intervention as necessary to serve the public interest, to prevent chaotic interference, and to compensate for inequity in market resource allocation. For example, the public interest mandate can justify regulatory intervention to promote localism, a policy initiative aiming to achieve widespread geographical coverage of broadcast radio and television stations, particularly in rural areas, at the expense of reducing the total number of broadcast outlets, particularly in urban areas.

44 White, supra note 8 , at 21 .

45 "The public interest standard gives rise to a regulatory architecture that is generally hostile to efficiency. Consumer interests are dependably eclipsed by special interests." Thomas W. Hazlett, The Wireless Craze, The Unlimited Bandwidth Myth, the Spectrum Auction Faux Pas, and the Punchline to Ronald Coase's "Big Joke": An Essay on Airwave Allocation Policy, 14 HARV. J.L. \& TECH. 335, 403 (2001) [hereinafter Hazlett, The Wireless Craze]. "[S]pectrum regulation is not mandated to advance consumer welfare, and the structure yielded by the public interest standard protects incumbent licensees at the expense of efficiency." Id. at 405.

46 Id at 452 . 
The public interest mandate also justifies a variety of behaviorshaping regulations ostensibly designed to accrue public benefits from the private use of spectrum selected from a larger pool of applicants. Put another way, public interest regulations impose a quantifiable tax on spectrum use in the sense that users may have to modify their spectrum use in ways that reduce the value of the spectrum to them, but perhaps increase the value to public beneficiaries and consumers of the services provided. A commercial television broadcaster might air public affairs programming-e.g., roundtable political discussions, fully recognizing that audience ratings will decline as comparatively fewer viewers prefer such content.

National regulatory agencies also justify their intervention on the perceived need to serve as a "traffic cop of the airwaves." 47 Until recently, regulators rejected the adaptation of real estate zoning laws for spectrum management as insufficient to protect the national interest and to serve social objectives. Regulators also have insulated government users, including the defense, intelligencegathering, antiterrorism, and public safety agencies, from having to compete and pay for spectrum. Many regulators initially objected to a one-time national "clearance sale" of valuable national resources, particularly in light of the fact that a property conveyance mechanism would vest ownership in wealthy individuals or corporations who would have little interest in equity concerns.

Officials in some national regulatory agencies have characterized the shortcomings in spectrum ownership as market failure. This concept views market resource allocation as unable to accommodate societal concerns such as promoting access by the poor and the politically unconnected and serving market-countervailing objectives that would not maximize profits, but might promote public policy objectives such as education, national defense, homeland security, and public safety.

\subsection{Competitive Bidding}

Notwithstanding long-term opposition, governments in both developed and developing countries have authorized competitive bidding for select portions of radio spectrum, particularly that allo-

47 "[T]ransmission interference has been considered fundamental and has provided the tried-and-true justification for the rejection of explicit property rights and for the adoption of a system of Federal stewardship and allencompassing regulation." White, supra note 8 , at 21. 
cated for domestic mobile telephone services. ${ }^{48}$ Generally these spectrum auctions confer an exclusive operating permit for a sizeable time, but do not constitute a transfer of property ownership rights. These auctions have generated a substantial financial windfall for governments' treasuries, and certainly extract the previously hidden public value in government awards of operating permits. ${ }^{49}$ When governments grant licenses, "[r]adio spectrum, as allocated to the license, is used at a price of zero." 50 The licensee captures all of what economists term "rent" -i.e., the stream of revenues and profits flowing from the use of spectrum as well as the heightened value that may arise in view of spectrum allocation decisions that may have created a scarcity of frequencies available for a particular use. By requiring prospective spectrum users to vote with their pocketbooks, governments effectively extract the value of spectrum use that operators previously captured exclusively. In application, the government conducts a public auction where previously spectrum licensees had the opportunity to conduct private auctions when selling their licenses at prices well in excess of the book value of the tangible assets used to provide services using radiocommunications resources. ${ }^{51}$

Spectrum auctions parallel other types of competitive bidding opportunities that governments set up when seeking revenue for conferring private use of public resources. Governments award private operating franchises in such diverse areas as oil and natural gas drilling, hotels and other commercial concessions at national parks, and animal grazing privileges on public property. In addition to extracting money for the national treasury, spectrum auctions can reduce delays in the issuance of operating authority. They should achieve greater efficiency in the use of spectrum as

48 See, e.g., Christopher J. Banks, The Third Generation of Wireless Communications: The Intersection of Policy, Technology, and Popular Culture, 32 LAW \& POL'Y INT'L BUS. 585 (2001) (describing wireless systems and regulations of four different countries); D. Daniel Sokol, The European Mobile 3G UMTS Process: Lessons From The Spectrum Auctions and Beauty Contests, 6 VA. J.L. \& TECH. 17 (2001) (discussing auction theory and licensing processes in diverse nations).

49 See Jill Carroll, Airwaves Auction Pulls in \$16.68 Billion, WALL ST. J., Jan. 29, 2001, at B8 (noting the value of U.S. airwaves); Reuters, Airwaves Sale Sets Record, $\$ 16.86$ Billion, N.Y. TIMEs, Jan. 27, 2001, at C14 (same).

50 Hazlett, The Wireless Craze, supra note 45 , at 457.

51 In the United States, before the FCC imposed anti-trafficking rules, spectrum licensees could accrue sizeable profits by quickly selling their operating permits even without having incurred any expense in the construction of the facilities needed to provide a service. 
competitive bidding typically confers greater operating flexibility: winning bidders will provide services designed to maximize the value of the spectrum and expedite the accrual of revenues needed to recoup the amount bid at auction. Likewise, winning bidders may accrue operating efficiencies by aggregating spectrum, within the limits imposed by spectrum caps to foreclose monopolizing the market for particular services. 52

\subsection{Technological Remedies to Spectrum Scarcity}

Technological innovations also offer ways to reduce the potential for interference and to promote greater spectrum sharing. Digital signal processing, ${ }^{53}$ frequency-agile transceivers, and software-managed spectrum use provide unprecedented opportunities to abate spectrum scarcity and congestion. ${ }^{54}$ By converting signals into a coded, digital sequence, which is a format compatible to the language of computers, engineers provide a way to streamline content delivery. A compressed digital signal can fit in a smaller channel thereby making it possible for more content to be transmitted. Frequency-agile radios hop and skip across various frequencies to avoid interference and to accommodate many users. Software adds intelligence and computation capabilities to transmitters and receivers thereby expanding total content output and abating the potential for interference.

In an environment where virtually unlimited spectrum access is technologically possible, governments need not micromanage spectrum use, provided they establish technical standards for the

52 In December, 2001 the FCC decided on a cap on spectrum available to a single operator providing commercial mobile radio services such as cellular radiotelephone and personal communications services. See 2000 Biennial Regulatory Review Spectrum Aggregation Limits for Commercial Mobile Radio Services, WT Docket No. 01-14, Report and Order, 16 F.C.C.R. 22,668 (2002) (eliminating the spectrum cap rule effective January 1, 2003 and immediately raising the cap from $45 \mathrm{MHz}$ to $55 \mathrm{MHz}$ in all markets).

53 "Due to advances in digital signal processing and antenna technology, communications systems and devices are becoming more tolerant of interference through their ability to sense and adapt to the R[adio] F[requency] environment." Spectrum Policy Task Force, Federal Communications Commission, Report of the Interference Protection Working Group 5 (Nov. 15, 2002), available at http://www.fcc.gov/sptf/files/IPWGFinalReport.pdf.

54 "'Frequency-agile technology via software-defined radio technology can be used to monitor power in spectrum bands and thus determine where channels might not be used or not available for licensed services due to buildout and deployment or environmental or topological considerations."' Id. at 12 (quoting comments filed by Personal Telecom Tech, Inc.). 
equipment and the transmission standards used by radio transmitting equipment. This approach considers spectrum a shared "commons" much like a public park where private ownership and property rights need not exist. .5

On a limited basis, governments have permitted this "spectrum commons" approach by allocating spectrum for low-powered, unlicensed use. Examples in the United States include citizens band radio, 56 a higher frequency alternative known as the Family Radio Service, ${ }^{57}$ a variety of unlicensed services under Part 15 of the Federal Communications Commission ("FCC") Rules, including baby monitors, garage door openers, model airplane controllers, and cordless telephones, 58 and wideband, wireless data services $^{59}$ including the increasingly popular Wireless Fidelity ("WiFi") alternative to cellular radio and other metered, pay by the minute, wireless data services. ${ }^{60}$ Heretofore most spectrum com-

55 For background on the concept of a commons as applied to spectrum use, see Benkler, supra note 8, at 394; Buck, supra note 8, at 2; Noam, supra note 8 , at $768,778-80$.

56 The Commission defines the Citizens Band Radio Service as "a private, two-way, short-distance voice communications service for personal or business activities of the general public." In the CB Radio Service, users may transmit communications about their personal or business activities, emergencies, and traveler assistance, but users must limit their communications to the minimum practicable time.

Notice of Proposed Rulemaking and Order, Amendment of the Commission's Rules Regarding Dedicated Short-Range Communication Services in the 5.850$5.925 \mathrm{GHz}$ Band (5.9 GHz Band), WT Docket No. 01-90, 2002 WL 31526787 (F.C.C. Nov. 15, 2002).

57 "The Family Radio Service (FRS) - a private, two-way, very short-distance voice communications service for facilitating family and group activities." 47 C.F.R. \$ 95.401(b) (2001).

58 See 47 C.F.R. Part 15 (2001) ("Radio Frequency Devices"); Review of Part 15 and Other Parts of the Commission's Rules, ET Docket 01-278, Notice of Proposed Rulemaking and Order, 16 F.C.C.R. 18,205 (2001) (reviewing and updating parts of the FCC rules including remote frequency devices).

59 See, e.g., Amendment of Part 15 of the Commission's Rules Regarding Spread Spectrum Devices, ET Docket No. 99-231, Second Report and Order, 17 F.C.C.R. 10,755 (2002) (improving spectrum sharing by unlicensed devices); Revision of Part 15 of the Commission's Rules Regarding Ultra-Wideband Transmission Systems, ET Docket No. 98-153, Erratum, 17 F.C.C.R. 10,505 (2002) (correcting errors in original Part 15).

60 Short-range data transmission is device-to-device communication over short distances, typically via unlicensed spectrum. The three main shortrange data transmission technologies are infrared, Bluetooth, and Wireless Fidelity ("WiFi"). Infrared, a well-established technology, is currently used in some PDAs to allow users to transfer data between two 
mons services quickly became congested, unreliable, and interference-ridden as the number of users increased. Some users responded by illegally increasing their transmission power thereby increasing the likelihood of harmful interference.

New computationally-intensive spectrum-hopping and codesequencing spectrum uses offer the potential for solving "tragedy of the commons" congestion resulting from overuse. Unlicensed WiFi usage has become quite popular, ${ }^{61}$ much to the chagrin of cellular radio and other wireless licensees that paid sizeable sums for their operating authority. Currently one cannot dismiss the technological innovations as inadequate or inferior to the property ownership alternative. However, the potential still exists for congestion, and technological solutions require the coordination and use of expensive new technologies.

devices. Infrared is also the technology commonly used in remote controls and requires line-of-sight transmission. Bluetooth enables multipoint, broadcasting applications, and WiFi enables devices to connect to wireless local area networks ("WLAN")....

... Bluetooth is a technology used to establish wireless connectivity between electronic devices that are up to 10 meters apart. Bluetooth allows users to send signals and transfer data among numerous electronic devices, thus creating a personal area network ("PAN"). Bluetooth uses unlicensed spectrum in the $2.4 \mathrm{GHz}$ band and transmits data at speeds close to one Mbps. Bluetooth also uses frequency hopping spread spectrum techniques to provide enhanced communications performance and an initial level of transmission security.

Implementation of Section 6002(b) of the Omnibus Budget Reconciliation Act of 1993, Annual Report and Analysis of Competitive Market Conditions with Respect to Commercial Mobile Services, Seventh Report, 17 F.C.C.R. 12,985, 13,061 (2002).

61 Another wireless networking technology sharing the $2.4 \mathrm{GHz}$ frequency band with Bluetooth is the Institute of Electrical and Electronics Engineers ("IEEE") 802.11b standard, also called WiFi. The $802.11 \mathrm{~b}$ standard is used to connect devices to WLANs, and allows a maximum throughput of $11 \mathrm{Mbps}$. Analysts have made several predictions about the growth of the WLAN market and WiFi. Frost \& Sullivan predicts that WLAN industry revenues will reach $\$ 884$ million by 2002 , compared to $\$ 415$ million in revenues forecast in 1999 . The Dell'Oro Group expects the WiFi market to grow by 35 percent in 2002. Gartner Group estimates 95 percent of notebook computers will be 802.11 b-enabled by 2005 .

Id. at 13,062 . 


\subsection{Problems in Competitive Bidding and Technological Congestion Remedies}

Despite their glowing endorsements, spectrum auctions and technological innovations do not completely remedy the inherent deficiencies in administrative allocation and licensing spectrum. Advocates for "propertizing" and "monetizing" spectrum scoff at lofty, but vague notions of the public interest and national security: "[ $\mathrm{t}]$ he 'public interest' with respect to the use of spectrum is a vague, ill-defined concept. Under the 'public interest' banner the Congress and the FCC have established far too many protectionist, anti-competitive, anti-innovative, inflexible, output-limiting regulatory regimes." 62 However defective in implementation, serving the public interest can achieve desirable social outcomes. Put another way, implementation of a marketplace resource allocation can frustrate efforts to achieve social goals. Additionally, in this age of heightened concerns about terrorism and national security, it comes across as rather cavalier ${ }^{63}$ to suggest that because everything is scarce, government defense, intelligence gathering, homeland security, and public safety agencies should pay for spectrum along with everyone else..$^{64}$

Advocates for competitive bidding also have to recognize the mixed record generated so far. Perhaps because governments successfully tailored auctions to extract maximum revenues, the outcomes have included several instances where bidders could not come up with the full amount, resulting in default and bankruptcy. Conflicts between bankruptcy and communications law in the United States ${ }^{65}$ have resulted in uncertainty whether the defaulted

62 White, supra note 8 , at 35 .

63 Under the property rights system ... governments would still have the ability to own and use spectrum parcels in ways that taxpayers felt were worthwhile, including defense and public safety, public broadcasting, etc. in the same way (and subject to the same constraints) that public agencies can own and use other forms of property.

Id.

64 "In principal, we think that government users should acquire spectrum at market prices the same way they acquire other inputs such as oil, real estate, and computer equipment. Paying market prices for these other inputs does not diminish the quality of government services." KWEREL \& WILLAMS, supra note 13, at 29.

65 When a licensee goes bankrupt, tension arises if the FCC tries to use its position as a regulator to give it an advantage as a creditor. The question is whether courts should treat the FCC as a creditor or as a regulator in Chapter 11 bankruptcy proceedings involving electromagnetic spectrum 
spectrum awards remain in the bankruptcy estate, administered by a court of law, or become available for reauction by the FCC. 66

Competitive bidding for spectrum earmarked for thirdgeneration mobile telephone and high-speed data services has generated astronomical amounts in the United States and nations in the European Union. However, a change in the overall marketplace attractiveness of telecommunications and informationprocessing ventures has jeopardized the operators' ability to recoup amounts bid for spectrum in a timely manner. Spectrum bidding has so raised debt exposure and risk that traditionally blue chip incumbent telecommunications ventures, such as British Telecom, Deutsche Telekom, AT\&T, and France Telecom, have incurred significant downgrades in the quality classification of their debt thereby raising their cost of raising capital. Similarly, the substantial near-term increase in debt and financial losses has a direct and substantial impact on the long-term tax liability and payments made by these firms.

While competitive bidding advocates may emphasize the potential for scale economies in the ability of firms to aggregate spectrum, opponents note the likelihood for concentration of owner-

licensees. The FCC's dual role has led the Second, Fifth, and D.C. Circuits to reach different and conflicting conclusions regarding the scope of the FCC's regulatory power in such proceedings.

The courts' efforts to reconcile the FCC's roles are made difficult because of tension between a primary goal of bankruptcy and the Bankruptcy Code's deference to governmental units acting in their regulatory capacities.

Nicholas J. Patterson, The Nature and Scope of the FCC's Regulatory Power in the Wake of the Nextwave and GWI PCS Cases, 69 U. CHI. L. REv. 1373, 1374 (2002).

66 Courts have reached different outcomes in cases presenting similar facts. The Second Circuit ruled that FCC jurisdiction over spectrum matters was deemed to predominate. See In re NextWave Pers. Communications, Inc., 200 F.3d 43 (2d Cir. 1999) (holding that lower courts exceeded their jurisdiction by in effect intervening in the allocation of radio spectrum licenses, which was within the FCC's exclusive regulatory jurisdiction); on remand, In re NextWave Pers. Communications Inc., 244 B.R. 253 (Bankr. S.D.N.Y. 2000) (holding that the FCC waived its right to assert that the debtors' licenses had been cancelled). However, the D.C. Circuit, addressing identical facts, held that the FCC was subject to its jurisdiction under the Bankruptcy Code. NextWave Pers. Communications, Inc., v. FCC, 254 F.3d 130 (D.C. Cir. 2001). The Fifth Circuit sided with the Second Circuit holding that the bankruptcy and district courts had jurisdiction over the FCC in a bankruptcy proceeding involving a licensee. In re GWI PCS1, Inc., 230 F.3d 788 (5th Cir. 2000). Because of a conflict between Circuit Courts, the Supreme Court has granted certiorari in FCC v. NextWave Pers. Communications, Inc., 535 U.S. 904 (2002). 
ship and control, particularly if regulators waive or eliminate caps on the total amount of spectrum a single operator can control. Spectrum auction advocates note the potential that smaller parcels of spectrum property might become available on the market just as large parcels of real estate become subdivided. ${ }^{67}$ But as regards spectrum, and in particular highly contested spectrum such as that allocated for third-generation wireless services, the more likely outcome would be zealous consolidation of ownership to achieve a national coverage "footprint." Economists may herald the potential for an up-to-the-minute "spot" market for spectrum, as well as a "secondary" resale market, ${ }^{68}$ but such marketplaces have not yet developed to any significant degree even for largely fungible minutes of long-distance calling capacity, or for broadband links between nations. Much of the technological innovation supporting a spectrum commons would have to be in place for a spectrum spot market to exist, because access would shift between and among many users in different locations.

The existing spectrum-bidding regime in the United States coupled with corporate mergers and acquisitions and the FCC's nearterm elimination of mobile radio spectrum caps has already resulted in substantial consolidation and concentration of operators. Economists might argue that under a property-rights regime, ample spectrum might be converted to mobile radio use to abate allocational scarcity created by the previous ITU and national regulatory agency regimes. Again, this ease in conversion presupposes that frequency-agile transceivers and other cutting-edge technological innovations become standard equipment in the near term. This assumption might not prove true, particularly where a devel-

67 "[A] system of spectrum property rights would cause spectrum to look much like real estate: Smaller units of spectrum would be available to anyone who could pay the market price." White, supra note 8 , at 35 .

68 The FCC has conditionally endorsed the development of secondary markets. See Promoting Efficient Use of the Spectrum Through Elimination of Barriers to the Development of Secondary Markets, 15 F.C.C.R 24,203 (proposed Nov. 27, 2000 ) (opening proceedings to examine actions to remove unnecessary regulatory barriers to the development of more robust secondary markets in radio spectrum usage rights). See also Principles for Promoting the Efficient Use of Spectrum by Encouraging the Development of Secondary Markets, Policy Statement, 15 F.C.C.R 24,178 (Dec. 1, 2000) (setting forth the FCC's "plans for facilitating secondary markets for radio spectrum that will allow and encourage licensees to make all or portions of their assigned frequencies and/or service areas available to other entities and users"). 
oped nation lies physically next to one or more developing countries.

\subsection{Flaws in Exporting Domestic Spectrum Policy}

Advocates for competitive bidding blithely assume that what works domestically can extend to international, transborder services. ${ }^{69}$ However, the limitations of physics, politics, jurisdiction, and international treaties complicate the process and refute the simple assumption that treaties between governments could "extend the property rights system ... into the international realm."70 Transborder uses of spectrum require coordination among affected nations regardless of whether an administrative or property model applies. In the former case, the ITU has established procedures for conflict avoidance and resolution. The ITU responds to transborder radio signal penetration by erecting a spectrum registration process that calls upon nations to relinquish a small degree of sovereignty and independent spectrum use in exchange for reduced interference, transaction costs, and risk. If a property model were to replace the administrative model, the ITU or some organization would have to perform a similar coordination function, using financial compensation as the medium for acquiring and relinquishing ownership rights.

Using the ITU or some other body as a spectrum ownership exchange involves no less complexity than the current registration process. Indeed the prospect of securing financial compensation creates an even greater incentive for any and all nations to claim a spectrum ownership interest, if only to willingly part with it for cash. Currently, comparatively few nations claim the right to coordinate their existing or prospective spectrum and orbital slot usage with that proposed by a new applicant. The opportunity to demand and receive "easy money" probably would create incentives for a far greater percentage of nations qualified to demand either a coordination right or compensation to do so.

Spectrum auction advocates correctly note that completely domestic spectrum uses would not require coordination with, or transfer payments to, other nations. However, these advocates

69 "For those spectrum uses that could have international consequences, some international coordination is needed to minimize interference problems. But that coordination does not require domestic management of spectrum by the government." White, supra note 8, at 36-37.

70 Id. at 37. 
underestimate the percentage of spectrum uses that can cross borders. Likewise, they do not seem to recognize that nearly all spectrum uses by satellite and all orbital slot occupancies could trigger claims of potential conflicting uses between nations. Satellite signal footprints can illuminate as much as one-third of the earth's surface. Arguably each and every nation lying under that footprint might have an ownership claim just as they now have a right to participate in spectrum and orbital slot coordination with a new usage registrant.

On occasion developing nations have raised equity of access concerns about the ITU's first-filed, first-registered spectrum/orbital slot registration process. In the mid-1970s, several equatorial nations attempted to stake an ownership claim to satellite orbital slots lying 22,300 miles overhead. ${ }^{71}$ While these nations did not get very far in a clear-cut attempt to declare a portion of outer space as available for national appropriation, a competitive bidding scheme would do just that ${ }^{72}$ Equatorial nations that failed in staking an ownership claim, or that grew weary of ITU coordination lacking a financial payoff, surely would have renewed vigor if they could extract compensation in exchange for relinquishing their ownership rights.

Extending the domestic spectrum competitive bidding process internationally to satellite orbital arc usage has the potential to increase market entry costs substantially. It could also trigger delays in the launch of new satellites until every country possibly served by the satellite receives compensation, or otherwise abandons ownership claims to the spectrum used by the satellite as well as the orbital slot in which the satellite is parked.73

71 Some states expressed concern that the spacefaring powers will occupy all of the available slots. The states were concerned that this would result in the freezing out of any opportunities that the developing states might have for placing their own satellites into geostationary orbit. The equatorial states have also asserted that the absence of a commonlyagreed boundary for the beginning of outer space means that the nonappropriation language of the Outer Space Treaty is inapplicable to the geostationary arc.

Weaver, supra note 3 , at 228-29.

72 For an examination of whether competitive bidding is lawful despite the prohibition on national appropriation of outer space resources, see Cahill, supra note 4 , at 231 .

73 For a comprehensive argument against satellite spectrum auctions, see Charles L. Jackson et al., Public Harms Unique to Satellite Spectrum Auctions: A Study 


\subsection{Can Economic and Technological Strategies Work for Satellites?}

Economists and engineers favoring change in spectrum management strategies emphasize the potential for greater competition, flexibility, and availability of spectrum to serve growing requirements. Combining the concept of property ownership with technological innovations, advocates for change herald the possibility of an up-to-the-minute "spot" market for spectrum able to respond instantaneously to changes in supply and demand. Such a spot market conceivably could work, provided that the spectrum on the market is accessible in only one nation and the technological innovations eliminate the previously pesky problem of interference. Arguably, a spot market for spectrum could parallel the developing spot market for telecommunications capacity 74 and the short-term access to "occasional use" satellite transponder capacity. ${ }^{75}$ However, what theoretically might work domestically has even greater challenges and limitations internationally.

2.12.Property Ownership Violates the Prohibition on National Appropriation of Space Assets

Currently, nations secure priority access to spectrum and satellite orbital arc by successfully maneuvering through the ITU registration process. Priority access results from the voluntary acquiescence of nations without the abdication of possible future access. As well, such access does not constitute an ownership claim, the assertion of jurisdiction over a space asset, or a usurpation of an-

Prepared for the Satellite Industry Association (Mar. 18, 1996), available at http://www.spri.com/pdf/reports/sia/pubharms.pdf.

74 In a recent examination of international telecommunications traffic settlement arrangement, the FCC acknowledged the development of a spot market for capacity and minutes of use: "[W]e request that commenters provide further information about the existence of resale 'spot' markets that provide buying and selling opportunities for capacity on international circuits and how such market mechanisms may place downward pressure on international termination rates and consumer calling prices." FCC International Settlements Policy Reform: International Settlement Rates, \#28 (proposed Oct. 10, 2002), available at http:// hraunfoss.fcc.gov/edocs_public/attachmatch/FCC-02285A1.pdf.

75 "Occasional-use television or video service is the provision of satellite transmission capacity to third parties for their video and associated audio transmissions on short notice and for a short duration, usually on one-minute increments." Section 63.19 Application of Comsat Corporation, For Authority under Section 214 of the Communications Act to Discontinue the Provision of Occasional-Use Television, Occasional-Use IBS and Part-Time IBS Services, 16 F.C.C.R. 22,396, 22,397 (released Dec. 18, 2001). 
other nation's equal right to secure priority access rights through the legitimate and recognized procedures administered by the ITU. The ITU has successfully brokered complex and conflicting satellite orbital slot claims, albeit with delays and its increasing need for compensation to shore up its budget. Brokering ownership interests does not appear to shorten the time to resolution, even as it raises new complexities.

\subsection{Empowerment Opportunities for Developing Nations}

Privatization of satellite cooperatives, proliferating private satellite ventures, technological innovations, calls for market-driven spectrum ownership, and growing demand challenge the ability of the ITU to manage shared global telecommunication resources. Stakeholders grow increasingly impatient with the speed and effectiveness of ITU conflict avoidance and resolution. Indeed the ITU has not been able to prevent gaming the system through the registration of unnecessary paper satellites by nations keen on securing negotiation leverage or cash.

Notwithstanding increasing stress on multilateral policymaking and conflict resolution, new, but costly, technological innovations offer ways to abate spectrum congestion and interference. Digital transmissions can be compressed and coded in ways that reduce the amount of spectrum used and facilitate expanded, interference-free communications. Digital signal processing and software-defined radio also provide means of increasing simultaneous uses without interference. Perhaps one way to balance efficiency and equity concerns would involve requiring developed nations to implement spectrum conservation technologies on an expedited basis, thereby freeing spectrum for use by operators in developed nations. In recognition of their limited access to capital, perhaps spectrum users in developing nations might receive a temporary waiver of the requirement to use costly spectrum conservation technologies.

It should come as no surprise that stakeholders, regardless of national residence and wealth, seek access to spectrum at the lowest cost, but also with the greatest degree of certainty of noninterference. The ITU registration process, while not infallible, has provided a degree of certainty that all nations will respect a previously recorded spectrum use. When INTELSAT served as the primary global satellite carrier, concerns about orbital slot congestion did not exist. 
Advocates of competitive bidding for spectrum uses favor expanding the rights and entitlements that property-style ownership affords. Accordingly, prospective spectrum users in developed nations increasingly express a willingness to bid cash for spectrum in exchange for greater confidence that they can pursue their business plans without worries about interference and congestion.

Developing nations and their constituents also seek access to spectrum at the lowest cost. But perhaps these nations might forgo access or use less desirable orbital slots and spectrum in exchange for compensation or other types of accommodation. Because they cannot readily vie for auctioned spectrum, operators in developing nations will seek to maintain the status quo ITU registration process, or some sort of compensation, in exchange for not blocking and seeking to thwart market mechanisms. One should not underestimate the potential for developing nations to find their voice and extract concessions. They hold a voting majority at the ITU and while most matters do not result in a formal vote, these nations can shape the debate. In light of the fractious nature of previous debates on transborder data flow and north/south inequality, developed nations should take pains to avoid triggering another round by refraining from pressing too aggressively for market-based initiatives, or costly technological requirements.

\subsection{Risks in Competitive Bidding for Spectrum}

At the behest of economists and with the incentive to bolster the national treasury, some nations have licensed spectrum usage through competitive bidding. Many economists assert that extracting large financial bids for spectrum access maximizes social welfare, ensures that spectrum will be put to the best possible uses, and fosters efficiency. However, the outcome of recent auctions shows that short-term financial windfalls may also result in less tax revenue over the longer term, bid-rigging, ${ }^{76}$ overbidding leading to bankruptcies and confusion over who retains title to the spectrum, and the potential for market concentration.

76 See Owen M. Kendler, Comment, Auction Theory Can Complement Competition Law: Preventing Collusion in Europe's $3 G$ Spectrum Allocation, 23 U. PA. J. INT'L ECON. L. 153 (2002) (suggesting "that appropriate auction design can be used in tandem with competition law to prevent buyer cartels in auctions. Auctions, like other markets, are susceptible to collusion, yet competition law is not able to punish all violations of competition law or oligopolistic market distortions."). 
Developing nations may consider competitive bidding for spectrum a relatively painless way to shore up the national treasury, much like privatization of the government-owned Post Telephone and Telegraph Administration. However, one should appreciate the short term. One-shot injection of capital will be offset by factors that may result in less tax and other revenues accruing in the long term. Conferring greater aspects of ownership and control over spectrum makes it virtually impossible for national governments to impose public interest and public service obligations. Privatizing spectrum converts a shared global resource into something akin to a long-term usage franchise. Franchisees expect to treat their spectrum awards as private property over which government has limited authority.

The degree to which a national government has confidence in marketplace resource allocation constitutes a key factor in the nature of spectrum management for that nation. Nations having confidence in the ability of markets to operate and to maximize private and public benefits typically have a greater propensity to license spectrum through competitive bidding. Nations with less confidence in the utility of market-driven spectrum use, or ones that have experienced dissatisfaction with their initial spectrum auction, appear more inclined to use older regulatory models highlighting government oversight.

\section{RECOMMENDATIONS}

Developing nations need to extract concessions from developed nations in ways that do not come across as extortion. Historically, developing nations have gained little from rhetoric, grand unilateral proclamations, or from the private auction strategies of single nations such as Tonga. It does not appear that the ITU will expand the set of frequencies and services that it will reserve for future use by developing nations in the face of compelling current demand by users in developed countries.

The best strategy for disenfranchised nations appears to combine active participation in the ITU process coupled with resumption of cooperative investment pooling and extracting technological concessions from developed nations. Developing nations should take every opportunity to include equity issues in ITU deliberations, but in a way that does not block progress. Users in developed countries can conserve spectrum and reduce the potential for interference by implementing technological remedies that users 
in developing nations cannot afford to implement immediately. Accordingly, the ITU might establish a recommendation that couples additional spectrum and satellite orbital slot registrations with an affirmative duty borne by developed-nation stakeholders to implement spectrum conservation technologies.

Another option might involve the partial adoption of market resource allocation techniques. Instead of auctioning off spectrum, nations could engage in the trading of access rights. Pollution abatement strategies provide a helpful case study for spectrum management. Because developed nations create the most pollution, their producers might pay for the right to exceed a pollution threshold in lieu of having to bear the expense in reducing harmful emissions. In the United States, some less developed states generate comparatively less pollution than other more industrialized states. The United States Environmental Protection Agency ("EPA") is considering a proposal to allow manufacturers and other enterprises the opportunity to secure additional pollution "rights" from enterprises that generate comparatively less pollution whether through reduced production, or through pollution abatement investments. ${ }^{77}$ Perhaps a similar sort of transfer pay-

77 "Pollution credit trading has been promoted by economists for years and, in the United States, is finally being considered seriously to deal with problems ranging from air and water pollution to global warming and the loss of wetlands and biodiversity." Dennis M. King, Managing Environmental Trades: Lessons from Hollywood, Stockholm, and Houston, 32 ENVTL. L. REP. 11,317 (2002). See also Water Quality Trading Policy: Proposed Policy, 67 Fed. Reg. 34,709 (May 15, 2002) (inviting comments on the EPA's proposed policy to signal EPA support for soundlydesigned water quality trading programs developed by states and tribes); Dana L. Hoag \& Jennie S. Hughes-Popp, The Theory and Practice of Pollution Credit Trading in Water Quality Management, 19 REv. AGRIC. ECON. 252 (1997).

Under a pollution trading system, a regulatory agency establishes a performance goal for an industry or area and then allocates increments of allowable pollution to each business unit in the industry or area. Because the cost of meeting their performance-based goals will differ among firms, firms with low pollution control costs should invest in a lot of pollution control, and firms with high pollution control costs should invest in less. Marketable permits allow firms to exchange increments of their performance-based goals so that the marginal cost of pollution control is equal across firms, with some firms exceeding their allocated pollution increment and others falling short. An added benefit to the tradable permit system is that it should stimulate investment in cost-effective pollution control technology because firms that can reduce the cost of pollution control can benefit by selling their allocated pollution increments. 